\title{
Origin and Evolution of the Self-Organizing Cytoskeleton in the Network of Eukaryotic Organelles
}

\author{
Gáspár Jékely \\ Max Planck Institute for Developmental Biology, 72076 Tuebingen, Germany \\ Correspondence: gaspar.jekely@tuebingen.mpg.de
}

The eukaryotic cytoskeleton evolved from prokaryotic cytomotive filaments. Prokaryotic filament systems show bewildering structural and dynamic complexity and, in many aspects, prefigure the self-organizing properties of the eukaryotic cytoskeleton. Here, the dynamic properties of the prokaryotic and eukaryotic cytoskeleton are compared, and how these relate to function and evolution of organellar networks is discussed. The evolution of new aspects of filament dynamics in eukaryotes, including severing and branching, and the advent of molecular motors converted the eukaryotic cytoskeleton into a self-organizing "active gel," the dynamics of which can only be described with computational models. Advances in modeling and comparative genomics hold promise of a better understanding of the evolution of the self-organizing cytoskeleton in early eukaryotes, and its role in the evolution of novel eukaryotic functions, such as amoeboid motility, mitosis, and ciliary swimming.

$T_{\text {ha }}^{\text {he }}$ he eukaryotic cytoskeleton organizes space on the cellular scale and this organization influences almost every process in the cell. Organization depends on the mechanochemical properties of the cytoskeleton that dynamically maintain cell shape, position organelles, and macromolecules by trafficking, and drive locomotion via actin-rich cellular protrusions, ciliary beating, or ciliary gliding. The eukaryotic cytoskeleton is best described as an "active gel," a cross-linked network of polymers (gel) in which many of the links are active motors that can move the polymers relative to each other (Karsenti et al. 2006). Because prokaryotes have only cytoskeletal polymers but lack motor proteins, this "active gel” property clearly sets the eukaryotic cytoskeleton apart from prokaryotic filament systems.

Prokaryotes contain elaborate systems of several cytomotive filaments (Löwe and Amos 2009) that share many structural and dynamic features with eukaryotic actin filaments and microtubules (Löwe and Amos 1998; van den Ent et al. 2001). Prokaryotic cytoskeletal filaments may trace back to the first cells and may have originated as higher-order assemblies of enzymes (Noree et al. 2010; Barry and Gitai 2011). These cytomotive filaments are required for the segregation of low copy number plasmids, cell rigidity and cell-wall synthesis, cell division, and occasionally the organization of membranous organelles (Komeili et al. 2006;

Editors: Patrick J. Keeling and Eugene V. Koonin

Additional Perspectives on The Origin and Evolution of Eukaryotes available at www.cshperspectives.org

Copyright (C) 2014 Cold Spring Harbor Laboratory Press; all rights reserved; doi: 10.1101/cshperspect.a016030

Cite this article as Cold Spring Harb Perspect Biol 2014;6:a016030 
Thanbichler and Shapiro 2008; Löwe and Amos 2009). These functions are performed by dynamic filament-forming systems that harness the energy from nucleotide hydrolysis to generate forces either via bending or polymerization (Löwe and Amos 2009; Pilhofer and Jensen 2013). Although the identification of actin and tubulin homologs in prokaryotes is a major breakthrough, we are far from understanding the origin of the structural and dynamic complexity of the eukaryotic cytoskeleton.

Advances in genome sequencing and comparative genomics now allow a detailed reconstruction of the cytoskeletal components present in the last common ancestor of eukaryotes. These studies all point to an ancestrally complex cytoskeleton, with several families of motors (Wickstead and Gull 2007; Wickstead et al. 2010) and filament-associated proteins and other regulators in place (Jékely 2003; Richards and Cavalier-Smith 2005; Rivero and Cvrcková 2007; Chalkia et al. 2008; Eme et al. 2009; Fritz-Laylin et al. 2010; Eckert et al. 2011; Hammesfahr and Kollmar 2012). Genomic reconstructions and comparative cell biology of single-celled eukaryotes (Raikov 1994; Cavalier-Smith 2013) allow us to infer the cellular features of the ancestral eukaryote. These analyses indicate that amoeboid motility (FritzLaylin et al. 2010; although, see Cavalier-Smith 2013), cilia (Cavalier-Smith 2002; Mitchell 2004; Jékely and Arendt 2006; Satir et al. 2008), centrioles (Carvalho-Santos et al. 2010), phagocytosis (Cavalier-Smith 2002; Jékely 2007; Yutin et al. 2009), a midbody during cell division (Eme et al. 2009), mitosis (Raikov 1994), and meiosis (Ramesh et al. 2005) were all ancestral eukaryotic cellular features. The availability of functional information from organisms other than animals and yeasts (e.g., Chlamydomonas, Tetrahymena, Trypanosoma) also allow more reliable inferences about the ancestral functions of cytoskeletal components (i.e., not only their ancestral presence or absence) and their regulation (Demonchy et al. 2009; Lechtreck et al. 2009; Suryavanshi et al. 2010).

The ancestral complexity of the cytoskeleton in eukaryotes leaves a huge gap between prokaryotes and the earliest eukaryote we can reconstruct (provided that our rooting of the tree is correct) (Cavalier-Smith 2013). Nevertheless, we can attempt to infer the series of events that happened along the stem lineage, leading to the last common ancestor of eukaryotes. Meaningful answers will require the use of a combination of gene family history reconstructions (Wickstead and Gull 2007; Wickstead et al. 2010), transition analyses (Cavalier-Smith 2002), and computer simulations relevant to cell evolution (Jékely 2008).

\section{OVERVIEW OF CYTOSKELETAL FUNCTIONS IN PROKARYOTES AND EUKARYOTES}

In the first section, an overview of the functions and components of the cytoskeleton in prokaryotes and eukaryotes is provided. To obtain a general overview, cellular structures (e.g., cell wall, kinetochore) and cytoskeletal proteins of prokaryotes and eukaryotes are represented as networks (Figs. 1 and 2). In the networks, the nodes represent proteins or cellular structures and the edges represent the co-occurrence of terms in PubMed entries, used as a proxy for functional connections. The nodes are clustered based on an attractive force (Frickey and Lupas 2004) calculated as the number of entries in which the two terms co-occur divided by the number of entries in which the less frequent term occurs.

For prokaryotes, all filament types are represented in one map, although many of these are specific to certain taxa and do not coexist in the same cell (Fig. 1A). For eukaryotes, the budding yeast (Saccharomyces cerevisiae) cytoskeletal network (Fig. 1B) and a simplified human cytoskeletal network is depicted (Fig. 2) (eukaryotic cytoskeletal proteins were retrieved from UniProt database [www.uniprot.org] using the GO ID GO:0005856).

The prokaryotic network has three major modules, the plasmid partitioning systems, the cell division machinery (divisome) using the FtsZ contractile ring, and the MreB filament system involved in cell-wall synthesis and scaffolding.

Components of the first prokaryotic cytoskeletal module function in the positioning of 
Origin and Evolution of the Cytoskeleton

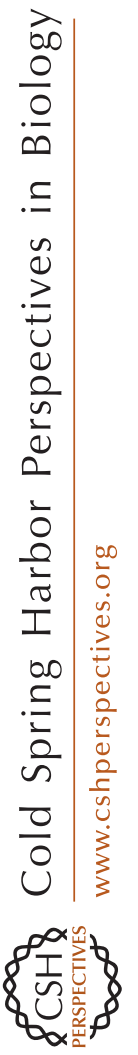

A
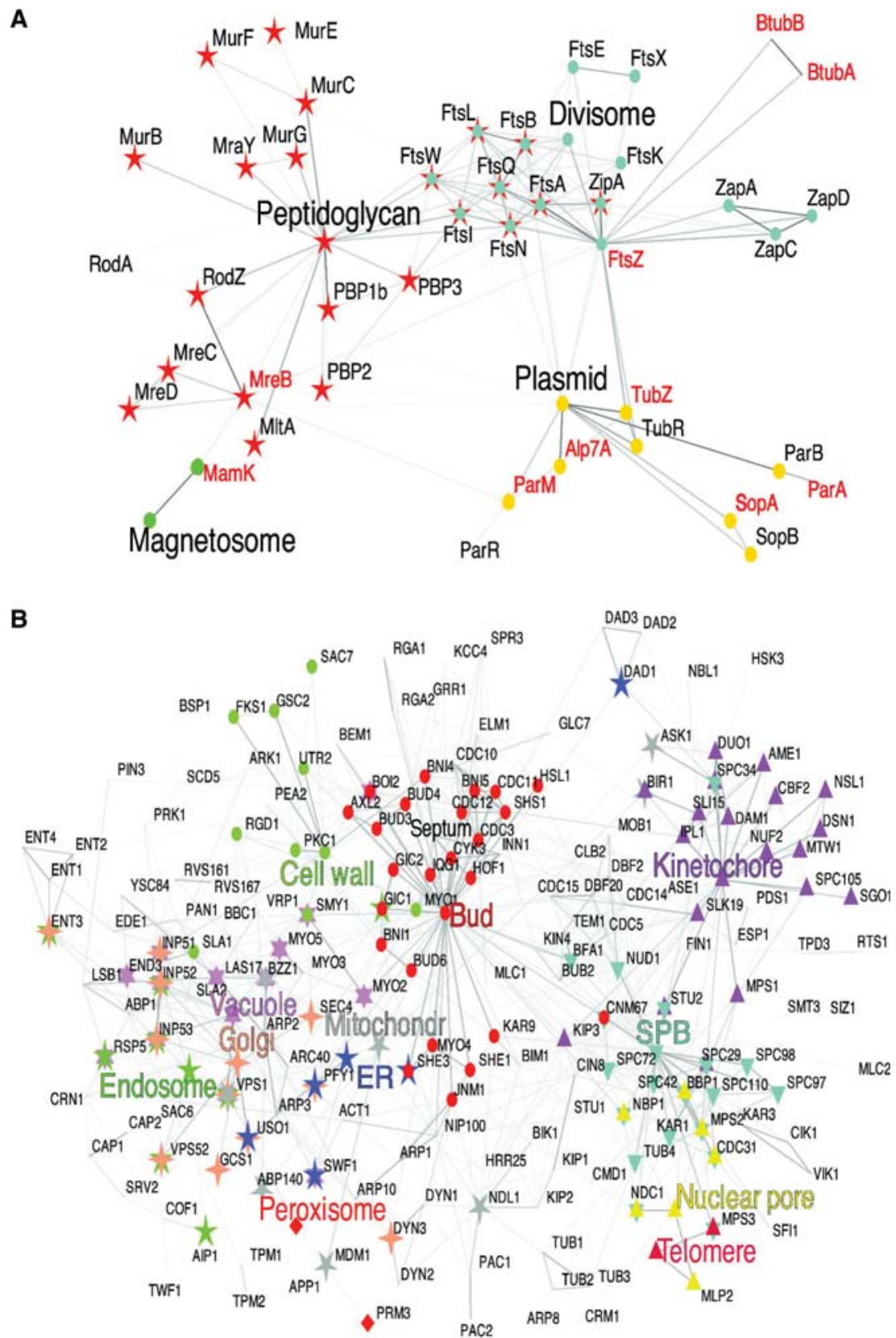

Figure 1. Prokaryotic and yeast cytoskeletal-organellar network. Cytoskeletal-organellar network of $(A)$ prokaryotes, and $(B)$ yeast. The nodes correspond to gene names or cytological terms.

DNA within the cell, driven by forces generated either by the polymerization or the depolymerization of filaments. These widespread and diverse filament systems are either responsible for the segregation of low copy number plasmids, or chromosome segregation (Pilhofer and Jensen 2013). DNA partitioning systems generally consist of a centromere-like region on DNA, a DNA-binding adaptor protein, and a filamentforming NTPase that polymerizes in a nucleo- 
G. Jékely

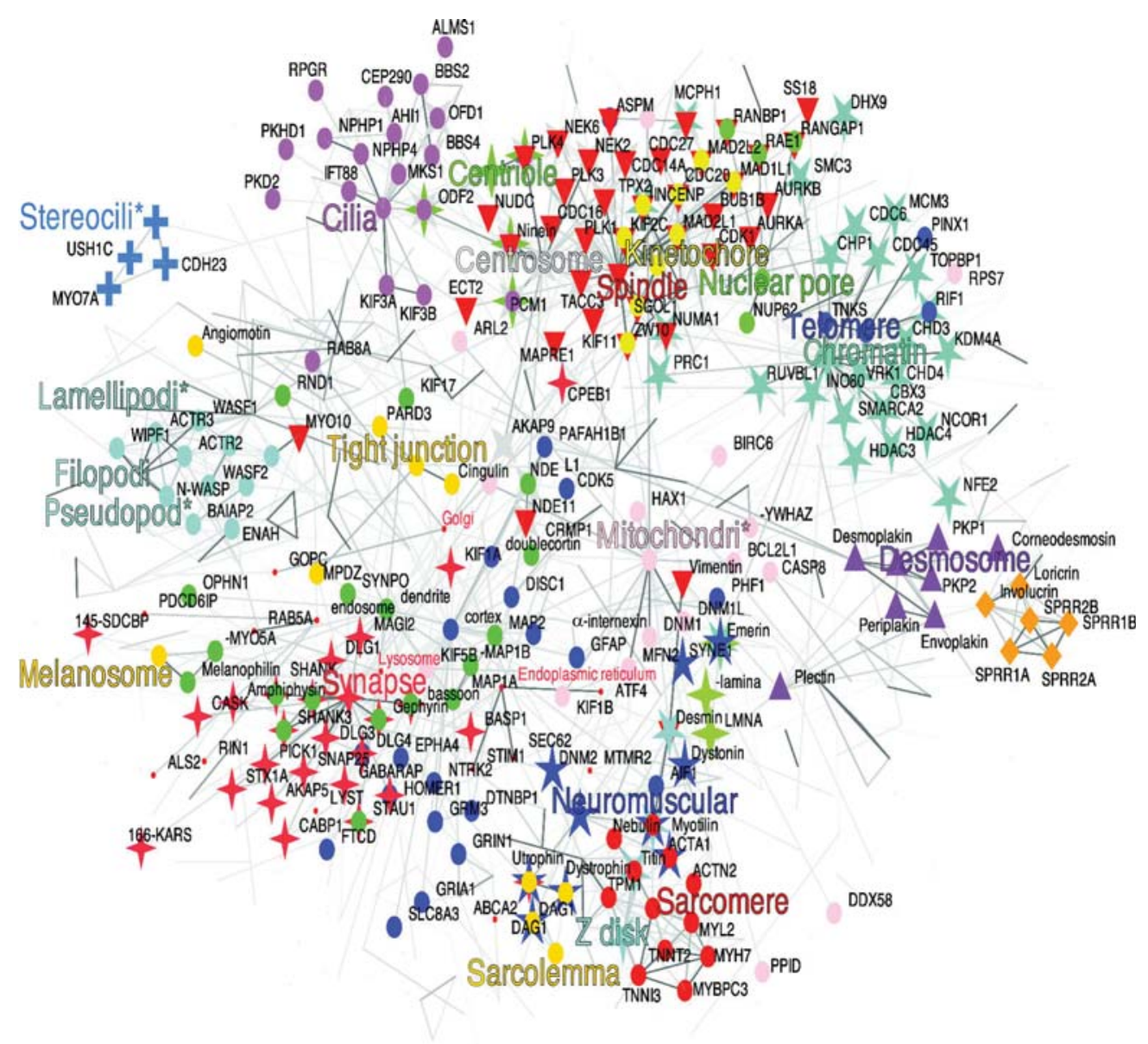

Figure 2. Human cytoskeletal-organellar network. The nodes correspond to gene names or cytological terms.

tide-dependent manner. Three types of filament systems have been described in prokaryotes. Type I systems use Walker ATPases (ParA-like), type II systems have actin-like ATPases (ParMlike), and type III systems have tubulin-like GTPases (TubZ-like).

The second widespread prokaryotic filament system functions in cell division. Cell division in all eubacteria and most archaebacteria relies on FtsZ-mediated binary fission. The tubulin-like GTPase, FtsZ (Löwe and Amos 1998), forms filaments that organize into a contractile ring ("Z-ring") at the cell center and trigger fission. The Z-ring is thought to be attached to the membrane at the division site by an "Aring," formed by the actin-like filament-forming protein, FtsA (Szwedziak et al. 2012). GTP- dependent FtsZ-filament bending may initiate membrane constriction (Osawa et al. 2009). The Z-ring also recruits several downstream components (e.g., FtsI, FtsW) that contribute to the remodeling of the peptidoglycan cell wall during septation (Lutkenhaus et al. 2012). In archaebacteria that lack a peptidoglycan wall and FtsA (bar one exception), cell division proceeds using a distinct, poorly understood machinery (Makarova et al. 2010).

The third prokaryotic filament system uses MreB, a homolog of actin that can form filaments in an ATP- or GTP-dependent manner (van den Ent et al. 2001). MreB is found in nonspherical bacteria and is involved in cell-shape maintenance by localizing cell-wall synthesis enzymes. MreB is linked to the peptidoglycan 
Origin and Evolution of the Cytoskeleton

precursor synthesis complex (Mur proteins and MraY) and the peptidoglycan assembly complex (PBPs and lytic enzymes, e.g., MltA). Loss of MreB leads to the growth of large, malformed cells that show membrane invaginations (Bendezu and de Boer 2008). In vitro MreB forms filament bundles and sheets (Popp et al. 2010c), whereas in vivo MreB filaments form patches under the inner membrane that move together with the cell-wall synthesis machinery, probably driven by peptidoglycan synthesis (Domínguez-Escobar et al. 2011; Garner et al. 2011). MreB filament patches also contribute to the mechanical rigidity of the cell, independent of their function in cell-wall synthesis (Wang et al. 2010).

The eukaryotic cytoskeletal networks (represented by yeast and human) include a celldivision module including the spindle, centromere, and centrosome (spindle pole body, SPB in yeast). This module functions in chromosome segregation, during which kinetochores must interact with spindle microtubules. Proper attachment is, for example, facilitated by Stu2 (ortholog of vertebrate XMAP215), a protein that is transferred to shrinking microtubule plus ends when they reach a kinetochore and stabilizes them (Gandhi et al. 2011). Other examples from this module are Aurora kinase and INCENP (yeast Ipl1 and Sli15), proteins that ensure that sister kinetochores attach to microtubules from opposite spindle poles during mitosis (Tanaka et al. 2002).

Another important subnetwork in the yeast cytoskeleton is involved in bud-site selection and the formation of a contractile actomyosin ring. An example in this network is yeast Myo1, a two-headed myosin-II that localizes to the division site and promotes the assembly of a contractile actomyosin ring and septum formation (Fang et al. 2010). The membrane trafficking subnetwork includes regulators of vesicle trafficking and cargo sorting, including the yeast dynamin-like GTPase, Vps1. Vps1 is involved in vacuolar, Golgi, and endocytic trafficking (Vater et al. 1992).

The human cytoskeletal network includes several other modules absent from yeast. These include a module centered around the cilium, and one module for the formation of lamellipodia, filopodia, and phagocytosis. The former includes ciliary transport (intraflagellar transport, BBSome), structural, and signaling (PKD2) proteins; the latter includes proteins that reorganize cortical actin filaments, including the Arp2/3 complex (ACTR2/3) (Mullins et al. 1998) and the Cdc42 effector N-WASP, an activator of the Arp2/3 complex (Takenawa and Miki 2001). The human network also contains several animal-specific modules, including modules related to stereocilia of inner-ear hair cells, muscle, neurons (dendrite, synapse), skin, and structures mediating cell-cell adhesion (desmosome).

Despite the vastly different organization and complexity of the eukaryotic and prokaryotic cytoskeletal networks, we know that there is evolutionary continuity between them. The eukaryotic cytoskeletal networks are centered around actin filaments and microtubules that evolved from homologous filament systems in prokaryotes (Löwe and Amos 1998; van den Ent et al. 2001).

\section{PROKARYOTIC ORIGIN OF THE MAJOR COMPONENTS OF THE EUKARYOTIC CYTOSKELETON}

In this section, an overview of the diversity of actin- and tubulin-like filament-forming proteins is given, and a few other key cytoskeletal components are discussed, for which distant prokaryotic homologs could be identified.

Besides actin- and tubulin-like filaments, prokaryotes also contain filament-forming Walker ATPases (ParA and SopA), with no polymer-forming homologs in eukaryotes. The evolution of this family will not be discussed.

\section{Origin of Eukaryotic Actin Filaments}

Actin is a member of the sugar kinase/HSP70/ actin superfamily (Bork et al. 1992). This family also includes different prokaryotic filamentforming proteins, including MreB, FtsA, the plasmid-partitioning protein ParM and its relatives, and an actin family specific to archaebacteria (crenactins). 
G. Jékely

To represent the diversity of actin-like proteins and their phyletic distribution in a global map, I clustered a large dataset of actin-like sequences based on pairwise BLASTP $P$ values using force-field-based clustering (Fig. 3A-C) (Frickey and Lupas 2004). Clustering can be very efficient if large numbers of sequences need to be analyzed. Given that, at least in prokaryotes, there is a tight link between orthologs and bidirectional best BLAST hits (Wolf and Koonin 2012). BLAST-based clustering can efficiently recover orthology groups in large data sets. Although clustering methods still lack sophisticated analysis tools that are common in alignment-based molecular phylogeny methods (e.g., rate heterogeneity among sites), the results from similarity-based clustering can agree well with molecular phylogeny (Jékely 2013; Mirabeau and Joly 2013). Cluster maps can also provide a general overview of taxonomic distribu- tion and sequence similarity, parameters that are not easily inferred from phylogenetic trees. Clustering is best thought of as a representation of sequence data as a similarity network, allowing evolutionary biologists to draw inferences about sequence evolution that are complementary to answers based on phylogeny (for a thoughtful introduction to the use of similarity networks, see Halary et al. 2013).

The actin similarity network revealed all actin-like protein families and their phyletic distribution. Filamentous actin was at the center of the cluster of eukaryotic actins and the diverse Arp families radiated from this center. The "centroid" position of actin (Fritz-Laylin et al. 2010) suggests that it represents the most ancestral eukaryotic sequence, and therefore maximizes all the blast hits to other eukaryotic actins. The ancestral nature of actin is also in agreement with its role in filament formation, where-
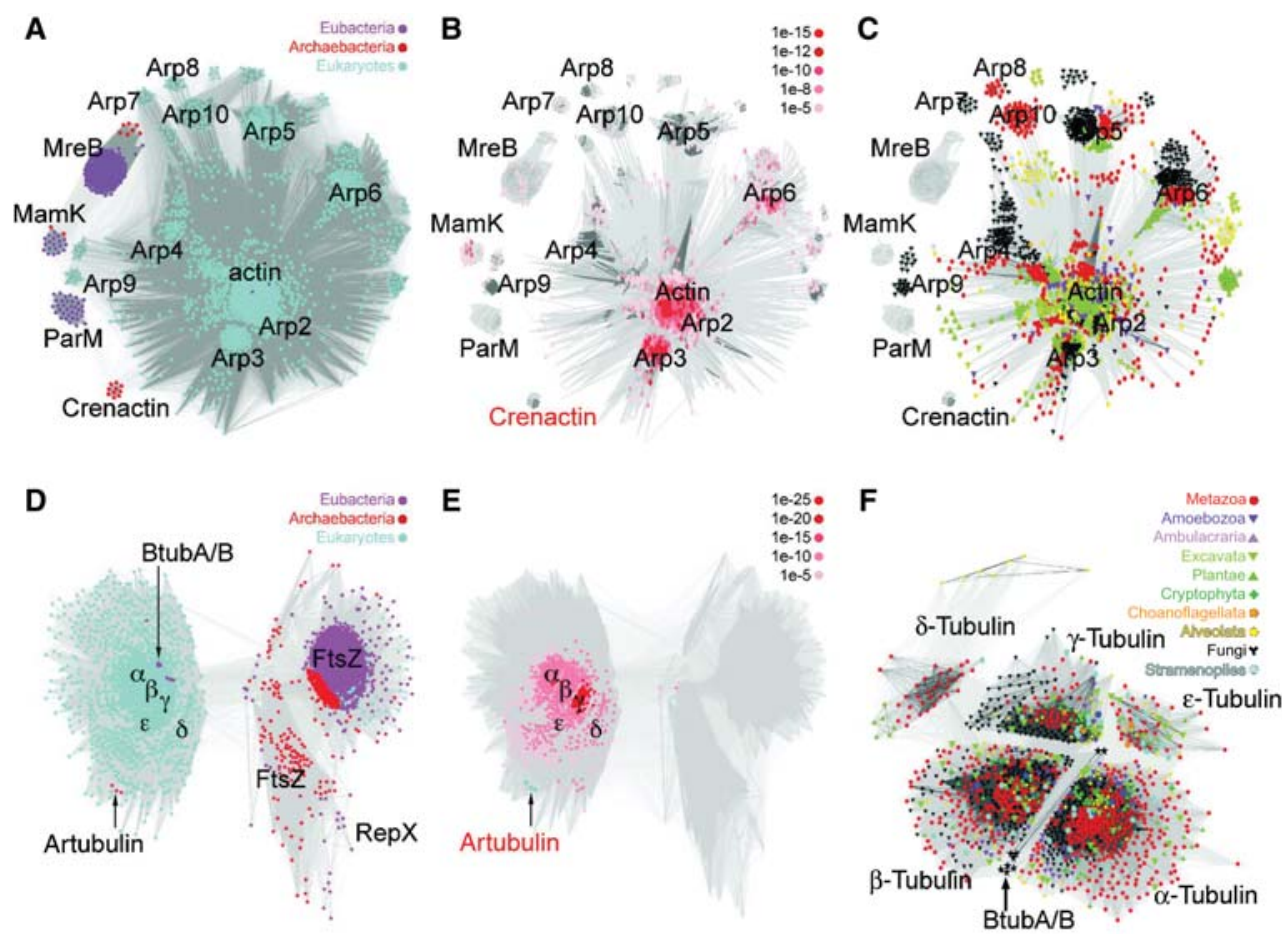

Figure 3. Cluster analysis of actin- and tubulin-like proteins. Sequence-similarity-based clustering was performed on $(A-C)$ prokaryotic and eukaryotic actin-like proteins, and $(D-F)$ prokaryotic and eukaryotic tubulinlike proteins. In both cases, an exhaustive, $90 \%$ nonredundant set of Uniprot is shown. The clusters were colored to reflect domain-wide $(A, D)$, or eukaryote-wide $(C, F)$ phyletic distribution. The BLASTP connections of $(B)$ crenactins, and $(E)$ artubulins were shown, with hits of different $P$-value cutoffs shown in different hues of red. 
as the more derived Arps are either regulators of filament branching and nucleation (the Arp2/3 complex) (Mullins et al. 1998), or have unrelated functions.

The similarity map also reveals the prokaryotic MreB, MamK, ParM, and crenactin families (the more derived FtsA was excluded) as distinct clusters. Among the prokaryotic actins, crenactins show the most similarity to eukaryotic actins and have been proposed to be the direct ancestors of eukaryotic actins (Yutin et al. 2009; Bernander et al. 2011). Crenactin was shown to form helical structures in Pyrobaculum cells, and is only found in rod-shaped archaebacteria (Ettema et al. 2011), indicating that it may regulate cell shape. Crenactins share two unique inserts with eukaryotic actins and other inserts that are uniquely shared with the actinlike protein Arp3 (Yutin et al. 2009). This is a puzzling observation and either suggests that Arp3 (arguably, a derived regulatory actin) represents the ancestral state, or crenactins originated via horizontal gene transfer (HGT) from eukaryotes to archaebacteria. The phylogenetic trees showing a sister relationship of crenactins to all eukaryotic actins (Yutin et al. 2009; Bernander et al. 2011) should be interpreted with caution, given that these trees have long internal branches, use very distant outgroups, and have few aligned positions. If crenactins were derived Arp3 proteins, they would also be expected to branch artificially at a deeper node, not as a sister to Arp3, because of long-branch attraction. Future structural studies of crenactins may be able to clarify the history of crenactins, relative to eukaryotic actins.

\section{Origin of Microtubules}

Microtubules are dynamic polymer tubes formed by 13 laterally interacting protofilaments of $\alpha / \beta$-tubulin heterodimers. Like actin filaments, microtubules are universal in eukaryotes. Besides the canonical $\alpha / \beta$-tubulins, several other tubulin forms have ancestrally been present in eukaryotes, including $\delta, \gamma$, and $\varepsilon$-tubulins. The prokaryotic homologs of tubulins include FtsZ, TubA, BtubA/BtubB from Verrucomicrobia, and artubulins, so far only found in the archaebacterium Nitrosoarchaeum (Yutin and Koonin 2012).

The cluster map of tubulins provides an overview of the phyletic distribution of all families (Fig. 3D-F). $\alpha, \beta, \gamma, \delta$, and $\varepsilon$-tubulins are all ancestrally present in eukaryotes, given their broad distribution and their presence in excavates, a protist group that potentially represents a divergence close to the root of the eukaryotic tree (Cavalier-Smith 2013). $\varepsilon$ and $\delta$-tubulin are only present in lineages with a cilium.

There are two independent, phyletically restricted groups of prokaryotic tubulins with higher sequence similarity to eukaryotic tubulins than FtsZ, BtubA/BtubB from Prosthecobacter, and the archaebacterial artubulins.

BtubA and BtubB were identified in Prosthecobacter (Jenkins et al. 2002), belonging to the Verrucomicrobia. These proteins show high-sequence (approximately 35\% identity) and structural similarity to eukaryotic $\alpha / \beta$-tubulins, and form tubulin-like protofilaments made up of BtubA/BtubB heterodimers (Schlieper et al. 2005). Despite the close similarity to $\alpha / \beta$-tubulins, there is no one-to-one correspondence between the $\alpha / \beta$ and BtubA/BtubB heterodimers. Instead, both BtubA and BtubB show structural features that are specific to either $\alpha$ or $\beta$-tubulin (Schlieper et al. 2005). This, together with the equal distance from $\alpha / \beta$-tubulin in sequence space (Fig. $3 \mathrm{~F}$ ), suggests that BtubA/BtubB represent a state in tubulin evolution preceding the duplication of $\alpha / \beta$-tubulins in stem eukaryotes. Because $\alpha / \beta$-tubulins are the structural components of microtubules, their origin by gene duplication was probably the first event in the history of eukaryotic tubulin duplications. The close similarity of BtubA/ BtubB to eukaryotic tubulins suggests that they originated by HGT from eukaryotes to Prosthecobacter (Schlieper et al. 2005).

Nevertheless, the ancestral character of BtubA/BtubB, uniting features of $\alpha / \beta$-tubulin suggests that BtubA/BtubB originated by an ancient HGT event, and these tubulins may provide insights into the early evolution of microtubules. Interestingly, and in contrast to all other prokaryotic tubulins, BtubA/BtubB can form tubules formed by five protofilaments (in- 
stead of 13 as in eukaryotes) (Pilhofer et al.2011). These simpler, smaller tubules may represent an intermediate stage in the evolution of the eukaryotic tubulin skeleton. The ability to form microtubules may also explain the higher sequence conservation of BtubA/BtubB, despite their potential early origin.

Another class of prokaryotic tubulins, artubulin, has recently been identified in Nitrosoarchaeum and has been proposed to be the ancestor of eukaryotic tubulins (Yutin and Koonin 2012). Artubulins show higher sequence similarity to eukaryotic tubulins than to FtsZ. In a phylogenetic tree, artubulins branched as a sister to all eukaryotic tubulins. In the cluster map, artubulins appear at the periphery of the eukaryotic tubulins (Fig. 3D), and show very low-sequence similarity to FtsZ. Coloring the nodes connected to artubulins according to their similarity (BLASTP value) to artubulins indicates that $\gamma$-tubulins are closest in sequence space. $\gamma$-Tubulin regulates microtubule nucleation and it is more likely that it represents a derived tubulin class, not one ancestral to $\alpha / \beta$ tubulins. These considerations, together with the very limited taxonomic distribution of artubulins cast further doubt on their ancestral status. The clustering results are consistent with artubulins representing a derived $\gamma$-tubulin, acquired by HGT from eukaryotes to Nitrosoarchaeum. The original molecular phylogeny may have grouped artubulins deep because of a long-branch artifact caused both by the derived nature of artubulins and the very distant outgroup. Structural analysis and polymerization assays of artubulins will help to better evaluate these alternative scenarios.

Overall, the origin of eukaryotic tubulin from either BtubA/BtubB or artubulins is not convincingly shown and both may have been acquired by HGT from eukaryotes. If this is the case, then the most likely ancestor of eukaryotic tubulins remains to be FtsZ.

\section{Origin of Molecular Motors}

Molecular motors are mechanochemical enzymes that use ATP hydrolysis to drive a mechanical cycle (Vale and Milligan 2000). Motors step either along microtubules (kinesins and dyneins) or the actin cytoskeleton (myosins) and are linked to and move cargo (molecules or organelles) around the cell. Several families of all three motor types are ancestrally present in eukaryotes (Richards and Cavalier-Smith 2005; Wickstead and Gull 2007; 2011; Wickstead et al. 2010).

The origin of motors is unknown because no direct prokaryotic ancestor has been identified. However, kinesins and myosins have common ancestry and share a catalytic core and a "relay helix" that transmits the conformational change in the catalytic core to the polymer binding sites and the mechanical elements (Kull et al. 1996). These motors are distantly related to and evolved from GTPase switches (Leipe et al. 2002), molecules that likewise undergo conformational changes on nucleotide binding and hydrolysis (Vale and Milligan 2000).

\section{Other Prokaryotic Homologs of Cytoskeletal Proteins}

The prokaryotic ancestry of cytoskeletal components other than actin and tubulin can also be ascertained by sensitive sequence and structural comparisons.

Profilin is a protein that breaks actin filaments (Schutt et al. 1993). Profile-profile searches with profilin using HHpred recovered the bacterial gliding protein MglB (Probab = 95.44, $E$ value $=0.73$ ) and other proteins with the related Roadblock/LC7 domain. Profilin and $\mathrm{MglB}$ also show structural similarity, as shown by PDBeFold searches (profilin 3d9y:B and MglB 3t1q:B with an RMSD of 2.65). The sequence- and structure-based similarities establish profilin as a homolog of the Roadblock family. In eukaryotes, members of this family are associated with ciliary and cytoplasmic dynein, and in prokaryotes, MglB is a GTPase activating protein of the gliding protein, the Raslike GTPase MglA (Leonardy et al. 2010).

The microtubule-severing factors katanin and spastin, members of the $\mathrm{AAA}^{+} \mathrm{ATPase}^{-}$ily, also have prokaryotic origin. $\mathrm{AAA}^{+}$ATPases have several ancient families with broad phyletic distribution, and the katanin family is a mem- 
Origin and Evolution of the Cytoskeleton

ber of the classical AAA clade (Iyer et al. 2004). This clade includes bacterial FtsH (an $\mathrm{AAA}^{+}$ ATPase with a carboxy-terminal metalloprotease domain), a protein that is localized to the septum in dividing Bacillus subtilis cells (Wehrl et al. 2000), in which it may degrade FtsZ (Anilkumar et al. 2001). Whether the katanin family of microtubule-severing factors evolved by the modification of FtsH is not resolved.

A third cytoskeletal regulator with prokaryotic ancestry is the enzyme $\alpha$-tubulin $N$ acetyltransferase (mec-17) that stabilizes microtubules in cilia and neurites by $\alpha$-tubulin acetylation. The phyletic distribution of this enzyme tightly parallels that of cilia. $\alpha$-Tubulin $N$-acetyltransferase is a member of the Gcn5-re- lated $N$-acetyltransferase superfamily (Steczkiewicz et al. 2006; Taschner et al. 2012), widespread in prokaryotes (Neuwald and Landsman 1997).

\section{DYNAMIC PROPERTIES OF THE PROKARYOTIC AND EUKARYOTIC CYTOSKELETON}

In the following section, the dynamic properties of the prokaryotic and eukaryotic cytoskeleton are compared. Prokaryotic filament-forming systems show remarkable properties that, in many respects, prefigure the dynamic, selforganized properties of the eukaryotic cytoskeleton (Fig. 4). The dynamic features of prokaryotic filaments include filament nucleation

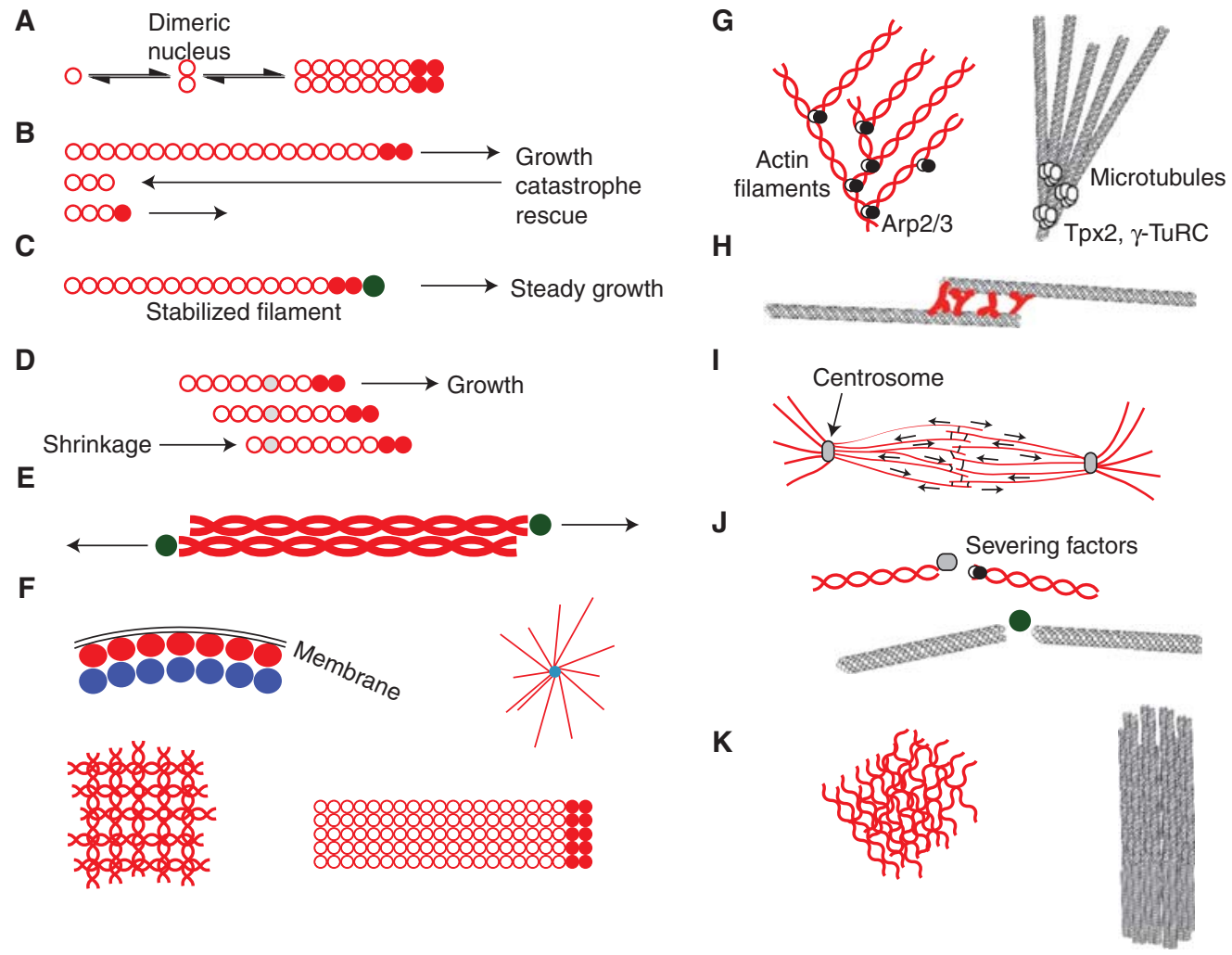

Figure 4. Dynamic properties of the cytoskeleton. Dynamic properties and self-organized patterns of the prokaryotic $(A-F)$, and eukaryotic $(G-K)$ cytoskeleton. $(A)$ Filament nucleation by a dimeric nucleus, $(B)$ dynamic instability, $(C)$ filament capping, $(D)$ treadmilling, $(E)$ bipolar growth of antiparallel filaments, and $(F)$ higher-order structures, such as filament pairs, asters, meshes, sheets. Eukaryotes, in addition, display $(G)$ filament branching, $(H)$ dynamic overlap of antiparallel filaments, $(I)$ spindle and asters, $(J)$ filament severing, and $(K)$ actin networks, axoneme, and basal bodies. 
G. Jékely

(Lim et al. 2005), polymerization and depolymerization, dynamic instability (Garner 2004), treadmilling (Larsen et al. 2007), directional polarization with plus and minus ends (Larsen et al. 2007), the formation of higher-order structures (Szwedziak et al. 2012), and force generation by filament growth, shrinkage, or bending. These features enable prokaryotic filaments to perform various functions such as the positioning of membranous organelles, chromosome and plasmid segregation, cell-shape changes, cell division, and contribution to the mechanical integrity of the cell (Wang et al. 2010).

The eukaryotic cytoskeleton shares all of the above features with the cytomotive filaments of prokaryotes (Fig. 4), but evolved additional features (Table 1). First, the dynamic properties shared between prokaryotes and eukaryotes are discussed. Then, an overview is given of the unique properties of the eukaryotic cytoskeleton that represent evolutionary innovations during the origin of eukaryotes.

Filament Nucleation, Polymerization, Depolymerization, and Capping

The regulation of the polymerization and depolymerization of polymers is essential for the proper functioning of filament systems. Filament growth can be influenced by various factors, including monomer concentration, nucleotides, and accessory factors, such as nucleating or polymerizing proteins. In eukaryotes, the spontaneous nucleation of microtubules and actin filaments is slow. Filament nucleation therefore represents an important regulatory component, allowing the positioning of growing filaments in the cell (Goley and Welch 2006; Kollman et al. 2011). In contrast, prokaryotic filaments commonly assemble rapidly and spontaneously, although nucleation may, in some cases, facilitate assembly. For example, FtsZ filament assembly proceeds via an FtsZ dimer that can serve as a nucleus for polymerization (Chen et al. 2005).

Cytoskeletal filament dynamics is also regulated by filament capping. Capping includes the binding of factors to the end of a filament, thereby preventing disassembly. Eukaryotic ac- tin fibers and microtubules are both regulated by capping (Cooper and Schafer 2000; Jiang and Akhmanova 2011). In prokaryotic DNA partitioning systems, filament assembly is commonly facilitated by the centromere-adaptor protein complex that stabilizes the growing end of the filament. This has been observed for all three types of prokaryotic filaments (Table 1) (Lim et al. 2005; Aylett et al. 2010; Kalliomaa-Sanford et al. 2012; Popp et al. 2012). Capping by the DNA-adaptor complex ensures the steady polymerization of the filaments by the incorporation of new subunits, thereby moving the plasmid or the chromosome (Salje and Löwe 2008; Kalliomaa-Sanford et al. 2012).

\section{Treadmilling}

Treadmilling is an important feature of eukaryotic actin (Wegner 1976) and microtubules (Shaw 2003), and is characterized by filament polymerization at one end and depolymerization at the other end. This results in the apparent motion of the filament, although the individual subunits stay in place. Treadmilling has also been observed in the actin-like and tubulinlike DNA segregation proteins (Table 1) (Kim et al. 2006; Larsen et al. 2007; Derman et al. 2009; Popp et al. 2010b, 2010c). Treadmilling of the tubulin-like protein TubZ was shown to be important for plasmid stability. TubZ with a mutation in a catalytic residue forms stable filaments that are unable to undergo treadmilling. The introduction of this mutant into the cell leads to the loss of the associated plasmid, highlighting the importance of filament dynamics for proper plasmid segregation (Larsen et al. 2007).

\section{Dynamic Instability}

Cytoskeletal filaments often show dynamic instability, characterized by the alternation of steady polymerization and catastrophic shrinkage. This behavior is also characteristic of eukaryotic microtubules (Mitchison and Kirschner 1984). Microtubules are polar, growing at their plus ends by the addition of tubulin heterodimers. Tubulins use GTP for filament as- 
Origin and Evolution of the Cytoskeleton

Table 1. Overview of the dynamic properties of prokaryotic and eukaryotic filament systems

\begin{tabular}{|c|c|c|c|c|c|}
\hline & $\begin{array}{c}\text { Prokaryotic actin- } \\
\text { like filaments }\end{array}$ & $\begin{array}{l}\text { Prokaryotic } \\
\text { tubulin-like } \\
\text { filaments }\end{array}$ & $\begin{array}{c}\text { Prokaryotic } \\
\text { Walker-ATPase } \\
\text { filaments }\end{array}$ & $\begin{array}{c}\text { Eukaryotic actin } \\
\text { filaments }\end{array}$ & $\begin{array}{c}\text { Eukaryotic } \\
\text { microtubules }\end{array}$ \\
\hline Capping & $\begin{array}{l}\text { ParM (Popp et al. } \\
\text { 2012) }\end{array}$ & $\begin{array}{l}\text { TubZ (Aylett } \\
\text { et al. 2010) }\end{array}$ & $\begin{array}{l}\text { SopA (Lim et al. } \\
\text { 2005), SegA } \\
\text { (Kallioma- } \\
\text { Sanford et al. } \\
\text { 2012) }\end{array}$ & $\begin{array}{l}\text { Cooper and } \\
\text { Schafer } 2000\end{array}$ & $\begin{array}{l}\text { Jiang and } \\
\text { Akhmanova } \\
2011\end{array}$ \\
\hline Treadmilling & $\begin{array}{l}\text { AlfA (Popp et al. } \\
\text { 2010b), MreB (Kim } \\
\text { et al. 2006; Popp } \\
\text { et al. 2010c), Alp7A } \\
\text { (Derman et al. } \\
\text { 2009) }\end{array}$ & $\begin{array}{r}\text { TubZ (Larsen } \\
\text { et al. 2007) }\end{array}$ & & Wegner 1976 & Shaw 2003 \\
\hline $\begin{array}{l}\text { Dynamic } \\
\text { instability }\end{array}$ & $\begin{array}{l}\text { ParM (Garner 2004), } \\
\text { Alp7 (Derman et al. } \\
\text { 2009; Drew and } \\
\text { Pogliano 2011) }\end{array}$ & & $\begin{array}{l}\text { SopA (Lim et al. } \\
\text { 2005) }\end{array}$ & & $\begin{array}{l}\text { Mitchison and } \\
\text { Kirschner } \\
1984\end{array}$ \\
\hline $\begin{array}{l}\text { Higher-order } \\
\text { structures }\end{array}$ & $\begin{array}{l}\text { ParM (Garner et al. } \\
\text { 2007; Gayathri et al. } \\
\text { 2012), MreB (Popp } \\
\text { et al. 2010c), FtsA } \\
\text { (Popp et al. 2010b; } \\
\text { Szwedziak et al. } \\
\text { 2012) }\end{array}$ & $\begin{array}{l}\text { FtsZ (Löwe } \\
\text { and Amos } \\
\text { 1999; } \\
\text { Popp et al. } \\
\text { 2010a; } \\
\text { Strauss } \\
\text { et al. 2012) }\end{array}$ & $\begin{array}{l}\text { SopA (Lim et al. } \\
\text { 2005) }\end{array}$ & $\begin{array}{l}\text { Vignaud et al. } \\
2012\end{array}$ & $\begin{array}{l}\text { Mitchell 2004; } \\
\text { Satir et al. } \\
2008\end{array}$ \\
\hline Severing & & & & $\begin{array}{l}\text { Cooper and } \\
\text { Schafer } 2000\end{array}$ & $\begin{array}{l}\text { Sharp and } \\
\text { Ross } 2012\end{array}$ \\
\hline Branching & & & & $\begin{array}{l}\text { Mullins et al. } \\
1998\end{array}$ & $\begin{array}{l}\text { Petry et al. } \\
2013\end{array}$ \\
\hline $\begin{array}{l}\text { Dynamic overlap } \\
\text { of antiparallel } \\
\text { fibers }\end{array}$ & & & & & $\begin{array}{l}\text { Bieling et al. } \\
2010\end{array}$ \\
\hline Molecular motors & & & & $\begin{array}{l}\text { Vale and } \\
\quad \text { Milligan } 2000\end{array}$ & Kull et al. 1996 \\
\hline
\end{tabular}

sembly, and GTP hydrolysis within the microtubule generates tension that is required for dynamic instability (Karsenti et al. 2006). Dynamic instability represents an efficient strategy to search in space (Holy and Leibler 1994). Dynamic instability is important for proper DNA capture and positioning in both prokaryotes and eukaryotes. The actin-like proteins ParM (Garner 2004) and Alp7 (Derman et al. 2009) were observed to undergo dynamic instability in vivo. The nucleotide-bound monomers form a cap that stabilizes the filament (Garner 2004), but on nucleotide hydrolysis, the filament rapidly disassembles. ParM filaments are polar, but when two filaments associate in an antiparallel fashion, they polarize bidirectionally (Gayathri et al. 2012). The filaments are dynamic and search the cell. Binding of the ParR/parC adaptor/centromere complex to the ends of ParM filaments inhibits dynamic instability, and promotes filament growth. This "search and capture" mechanism allows efficient plasmid segregation by pushing plasmids apart in a bipolar spindle.

The Walker ATPase SopA also forms dynamic filaments, the dynamics of which are important for plasmid segregation because mutants that form static polymers inhibit segre- 
gation (Lim et al. 2005). Filaments formed by the actin-like Alp7A also undergo dynamic instability, and computational modeling and experiments of an artificial system consisting of Alp7A and a plasmid revealed how such dynamic instability can drive the positioning of plasmids either to the cell center or the cell poles (Drew and Pogliano 2011). This bimodal system is tunable, and cell-center or cell-pole positioning depends on the parameters of dynamic instability. This simple system illustrates how a dynamic cytoskeletal system of a few components can create spatial inhomogeneity of macromolecules in the cell.

\section{Force Generation}

The eukaryotic cytoskeleton can generate force by at least three distinct mechanisms: filament growth, filament shrinkage (Kueh and Mitchison 2009; McIntosh et al. 2010), or molecular motors walking on filaments (Vale 2003). In prokaryotes, no motor has been found, and force is generated by filament growth, filament shrinkage, or filament bending (FtsZ). Nucleotide-driven filament growth relies on the continuous addition of subunits to the filament end, which can push the attached structures. This is the general mechanism of force generation for all three types of plasmid partitioning systems. Filament shrinkage has also been suggested as a mechanism of force generation during chromosome segregation in Caulobacter crescentus. The shrinkage of the ParA filament, destabilized by centromere-bound ParB, is thought to move the centromere to the cell poles through a "burnt-bridge Brownian ratchet" mechanism (Ptacin et al. 2010). Filament bending was proposed to exert force during FtsZmediated cell division (Osawa et al. 2009). Large filaments formed by the overexpression of the actin-like protein, FtsA, can also bend Escherichia coli cells (Szwedziak et al. 2012).

\section{Cooperation of Distinct Filament Types}

In eukaryotes, the actin and tubulin systems often work together, for example, at the midbody during cell division or during endocytosis when cargo vesicles switch from actin- to microtubule-based transport (Soldati and Schliwa 2006). Cooperation of distinct filament types also occurs in prokaryotes. In C. crescentus, the CtpS and crescentin filaments co-occur at the inner cell curvature and regulate each other. Crescentin recruits CtpS, and CtpS negatively regulates crescentin assembly (Ingerson-Mahar et al. 2010). A two-filament system is also important during FtsZ-mediated cell division. The tubulin-like GTPase forming the constriction ring, FtsZ, is recruited to the membrane by the actin-like protein FtsA. FtsA also forms filaments, and this ability has been shown to be important for proper cell division (Szwedziak et al. 2012). Polymerized FtsZ may be attached to the membrane by patches of polymerized, membrane-bound FtsA localized to the cell division ring. It has recently been found that FtsZ also directly interacts with $\mathrm{MreB}$, and this interaction is required for Z-ring contraction and septum synthesis (Fenton and Gerdes 2013).

\section{Higher-Order Filament Structures}

Eukaryotic filament systems generate several higher-order structures, including the ciliary axoneme, the mitotic spindle, microtubule asters, or contractile actin meshworks (Vignaud et al. 2012). Several prokaryotic filaments also form higher-order structures (Table 1). FtsZ can form toroids and multistranded helices, consisting of several filaments bundled together (Popp et al. 2010a). Pairs of parallel FtsZ filaments associated in an antiparallel fashion can form sheets (Löwe and Amos 1999). In vivo, FtsZ forms discontinuous patches in a beadlike arrangement at the cell division ring consisting of several filaments (Strauss et al. 2012). SopA is able to form aster-like structures in vitro, radiating from its binding partner, SopB, bound to a plasmid containing SopB-recognition-sites (Lim et al. 2005). The actin-like protein ParM is also able to form asters in vitro (Garner et al. 2007) and antiparallel filaments in the cell (Gayathri et al. 2012). MreB forms multilayered sheets with diagonally interwoven filaments, or long cables with parallel protofila- 
ments (Popp et al. 2010c). Filaments of the actin-homolog FtsA can also form large bundles when overexpressed in E. coli that can bend the cell and tubulate the membrane (Szwedziak et al. 2012). The bacterial actin AlfA can form three-dimensional (3D) bundles, rafts, and nets (Popp et al. 2010b).

This list is impressive and illustrates well the versatility of the prokaryotic cytoskeleton. However, the complexity of the higher-order structures formed by the eukaryotic cytoskeleton far surpasses the complexity of these structures. The eukaryotic cytoskeleton organizes cellular space using both dynamic scaffolds (e.g., mitotic spindle, microtubule aster, lamellipodia) and static scaffolds built of stabilized filaments (e.g., axoneme, microtubular ciliary root, microtubule-supported cell-cortex in several protists, stabilized microtubule bundles in metazoan neurites, microvilli, sarcomeres). The formation of these structures would not be possible without the unique dynamic properties of the eukaryotic cytoskeleton.

\section{Unique Dynamic Properties of the Eukaryotic Cytoskeleton}

The eukaryotic cytoskeleton has several novel properties, not yet described in prokaryotic filament systems. These include filament severing (actin fibers [Cooper and Schafer 2000] and microtubules [Sharp and Ross 2012]); branching (actin fibers [Mullins et al. 1998] and microtubules [Petry et al.2013] ), and dynamic overlap of the antiparallel fibers (microtubules [Bieling et al. 2010]). In addition to these novel properties, those properties that are shared by prokaryotic filaments also evolved additional layers of regulation. A host of accessory cytoskeletal factors appeared early in eukaryote evolution. For example, microtubule dynamics is regulated by nucleating ( $\gamma$-tubulin ring complex $[\gamma$-TuRC $]$ ), stabilizing (MAPs), destabilizing (stathmin, katanin), minus-end stabilizing (patronin/ssh4) (Goodwin and Vale 2010), and plus-end-tracking proteins (Jiang and Akhmanova 2011). Similarly, actin dynamics is also regulated by a range of accessory factors, mostly representing eukary- otic novelties (Rivero and Cvrcková 2007; Eckert et al. 2011).

The most dramatic innovation in eukaryotes is the use of molecular motors (Vale and Milligan 2000). Kinesins and myosins share a catalytic core that undergoes a conformational change on nucleotide binding and hydrolysis. This is transmitted by a "relay helix" to the polymer binding sites and the mechanical elements (Kull et al. 1996). Motor proteins are stepping along the filaments using such mechanochemical cycles. Motors are either nonprocessive or processive, depending on whether they perform one or multiple cycles before detaching from the filament. Processive motion enables longrange transport using one motor protein. A hypothetical evolutionary scheme for the evolution of processive motors from a GTPase is outlined in Figure 5.

The advent of motors added an extra layer of complexity to cytoskeletal dynamics. Motors perform diverse and specialized functions and are essential for the movement of organelles and complexes (e.g., intraflagellar transport), establishment of a bipolar spindle, definition of the cell division plane, cell migration, and cell polarity. For example, specific kinesin families are involved in the regulation of ciliary transport and motility (kinesin 2, 9, 13), and only occur in species with cilia (Wickstead et al. 2010). Others are involved in ciliary length control (Kif19) (Niwa et al. 2012). Some kinesins regulate different aspects of spindle organization including spindle midzone formation (kinesin-4, Kif14) (Kurasawa et al. 2004; Gruneberg et al. 2006), alignment on the metaphase plate (Xkid) (Antonio et al. 2000), or centrosome separation during bipolar spindle assembly (Eg5 [Kapitein et al. 2005]; Kif15 [Tanenbaum et al. 2009]).

The eukaryotic cytoskeleton forms complex $3 \mathrm{D}$ patterns by the dynamic interactions of filaments, motors and accessory proteins in a selforganizing process (Vignaud et al. 2012). The evolution of these new dynamic properties must have been tightly linked to the origin of novel cellular features during eukaryote origins. In the following section, some of the possible links in the framework of a cell evolutionary scenario will be discussed. 
G. Jékely

A

Nucleotide-dependent binding

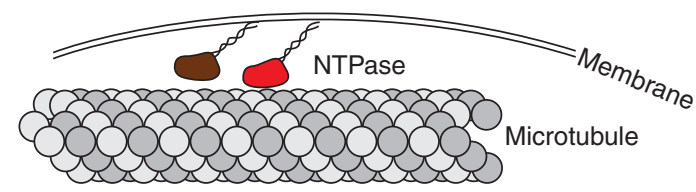

B
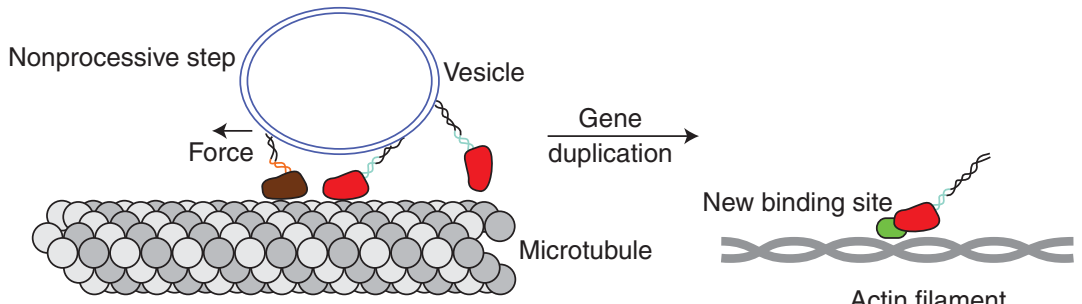

Actin filament

C

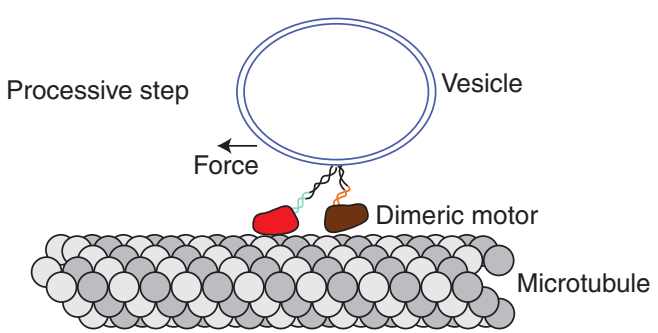

Figure 5. Evolutionary scenario for the origin of processive kinesin and myosin motors. Kinesin and myosin have a common origin and evolved from a GTPase switch. In the first stage, the NTPase is bound to the filament in a nucleotide-dependent manner via a short motif connected to the NTPase domain. The NTPase was engaged in other interactions (e.g., membrane binding), and recruited the filament to an organelle. In the next step, the mechanical elements evolve that can perform one mechanical cycle following the nucleotide cycle. Motion and dissociation are both coupled to the nucleotide cycle and are transduced via a relay helix that is conserved between kinesin and myosin. This nonprocessive motor can now exert force on the bound organelle (e.g., a vesicle). The clustering of several of these motors can move organelles. Monomeric motors may have been nonprocessive (Berliner et al. 1995), or may have used biased one-dimensional diffusion for processivity (Okada and Hirokawa 1999). Myosin and kinesin probably diverged at such a stage by the acquisition of a novel filamentbinding site and engagement with the second filament type (the direction is unclear). It is unlikely that the common ancestor of kinesin and myosin had a binding surface for both actin and tubulin filaments. Motor dimerization may have evolved to increase the probability of repeated engagement with the filaments. For processivity, the dimensions of the linker had to match the spacing of the accessible binding sites on the filament ( $80 \AA$ for microtubules, $360 \AA$ for actin filaments). This allowed the filament-dependent coupling of the nucleotide cycles on the two motor heads (the "mechanically controlled access" model) (Vale and Milligan 2000).

\section{COEVOLUTION OF A DYNAMIC AND SCAFFOLDING CYTOSKELETON WITH EUKARYOTIC ORGANELLES}

The origin of the eukaryotic cytoskeleton can be placed into a transition scenario of eukaryote origins. Such scenarios may seem like "just-so stories," but are nevertheless important concep- tual frameworks and can identify problems for future research. The first major event that could have precipitated a functional shift in the prokaryotic cytomotive filament systems could have been the loss of a rigid cell wall (CavalierSmith 2002). This step is necessary, irrespective of the prokaryotic lineage from which eukaryotes evolved (archaebacteria or the common 
ancestor of the sister groups archaebacteria and eukaryotes). The loss of the cell wall may have been a dramatic, but not lethal event. The recent discovery of cell division in wall-free bacteria via membrane blebbing and tubulation provides a model for cell division following cell-wall loss (Mercier et al. 2013). Importantly, wall-free division is independent of FtsZ, suggesting that in early eukaryote evolution the release of functional constraints may have allowed the rapid functional evolution of FtsZ. Similarly, a rapid shift in prokaryotic actin functions may also have been facilitated by cell-wall loss.

MreB directly contributes to the mechanical integrity of the bacterial cell, independent of its function in directing cell-wall synthesis (Wang et al. 2010). This suggests that the mechanical function of the filamentous cytoskeleton may have a prokaryotic origin. Loss of the cell wall may have triggered the elaboration of such a function and led to the evolution of actin networks involved in motility and cytokineses.

An important step in tubulin evolution was the origin of the microtubule, formed by the lateral association of protofilaments. Hollow tubes have higher mechanical rigidity and could have more efficiently served scaffolding and transport functions. Microtubules may have evolved into the 13-protofilament-form following the origin of the $\gamma$-TuRC complex that helped to fix the number of protofilaments.

A common theme in the evolution of actin and tubulin filaments is the early origin of paralogs involved in nucleating the filaments (Arp2/3 and $\gamma$-tubulin). FtsZ dimers can nucleate FtsZ filaments, and it is conceivable that a gene duplication event allowed the functional separation and streamlining of the filamentforming and nucleating functions for both filament types. The origin of separate nucleating factors allowed a more flexible positioning of nucleating centers, given that these could now be regulated independent of the filaments.

By providing support for membrane transport, the filaments facilitated the evolution of the endomembrane system (Jékely 2003). All endomembranes depend on cytoskeletal factors for their formation and transport. Early membrane dynamics may have evolved to allow en- docytic uptake of fluid and particles and deliver extra membrane to sites of phagocytic uptake. Phagocytosis can proceed even without a dynamic actin cytoskeleton, driven by thermal membrane fluctuations and ligand-receptor bonds that zipper the membrane around a particle. The origin of an actin network could have made this process more efficient by preventing the membrane from moving backward like a ratchet (Tollis et al. 2010). The origin of phagocytosis could have led to the origin of mitochondria (Cavalier-Smith 2002; Jékely 2007). Energetic arguments seem to favor an early origin of mitochondria (Lane and Martin 2010); however, complex, nucleotide-driven dynamic filament systems are abundant in prokaryotes and can drive membrane remodeling. For example, overexpression of the actin-like protein FtsA can lead to the formation of large, proteincoated intracellular membrane tubules (Szwedziak et al. 2012). In addition, amitochondrial eukaryotes can maintain a complex cytoskeleton (e.g., Trichomonas vaginalis has 19 kinesin and 41 dynein heavy chains), making the energetic argument for the primacy of mitochondria over phagotrophy less compelling.

The self-organizing properties of the cytoskeleton presumably evolved very early. We know from minimal systems and simulations that a few components are sufficient to organize complex, dynamic structures such as spindles, spirals, and aster (Leibler et al. 1997; Surrey 2001; Nédélec 2002; Nédélec et al. 2003). For example, one function of the dynamically unstable microtubule cytoskeleton is to position the nucleus in the cell center by exerting pushing forces on the nucleus (Tran et al. 2001). This process contributes to the spatial organization of the cell (e.g., by determining the cell division plane). Center positioning can also work in vitro with a minimal system of dynamic microtubules, even in the absence of motor proteins (Holy et al. 1997).

These examples illustrate that we have a growing understanding of the self-organization of dynamic cytoskeletal structures of various shapes and functions. In future studies, this knowledge could be combined with comparative genomic reconstructions to study "alter- 
native cytoskeletal landscapes" in different eukaryotic lineages (Dawson and Paredez 2013) and reconstruct the stepwise assembly of these self-organizing structures during the origin of eukaryotes.

\section{CONCLUDING REMARKS}

The complex self-organizing properties of the cytoskeleton set it apart from other cellular systems such as large macromolecular assemblies or metabolic pathways. This means that it is difficult to deduce what effects the addition or loss of one component might have had on the systems-level properties. This is in contrast to metabolic pathways, in which evolutionary changes can be efficiently modeled using fluxbalance analysis of the entire metabolic network of a cell (Pal et al. 2005). A similar analysis is not yet feasible for the entire cytoskeletal network. However, it would now be possible to study the evolution of subsystems from a systems perspective. Consider the mitotic spindle. We have a good understanding of how the antiparallel microtubule arrays overlapping at their plus ends form in a dynamic process involving an interplay of microtubule growth and shrinkage, motor activity, and proteins binding specifically to the overlap region (Janson et al. 2007). The emergence of a dynamic bipolar spindle can also be captured in computer simulations (Nédélec 2002). In evolutionary models, one would have to consider a succession of states following the gradual change of activities or addition of components. There are at least five ancestral kinesin families involved in mitosis (Wickstead et al. 2010). How did mitosis work when there was only one kinesin in a stem eukaryote?

The origin of axonemal motility, involving microtubule doublets and at least seven ancestral axonemal dynein families (Wickstead and Gull 2007), represents a similar problem. What was the beat pattern of the protocilium like with only one axonemal dynein? How did it change when inner-arm and outer-arm dyneins diverged? The origin of lamellipodial motility and phagocytosis could also be best addressed by focusing on minimal systems that allow the formation of membrane protrusions supported by an actin network (Gordon et al. 2012; Vignaud et al. 2012). Only a combination of mutant studies (Mitchell and Kang 1991), in vitro reconstituted systems (Takada and Kamiya 1994), comparative genomics (Wickstead and Gull 2007), and computer simulations (Brokaw 2004; Tollis et al. 2010) could answer these questions.

\section{ACKNOWLEDGMENTS}

I thank David R. Mitchell and Elizabeth Williams for their comments on the manuscript. The research leading to these results received funding from the European Research Council under the European Union's Seventh Framework Programme (FP7/2007-2013)/European Research Council Grant Agreement 260821.

\section{REFERENCES}

Anilkumar G, Srinivasan R, Anand SP, Ajitkumar P. 2001. Bacterial cell division protein FtsZ is a specific substrate for the AAA family protease FtsH. Microbiology 147: 516-517.

Antonio C, Ferby I, Wilhelm H, Jones M, Karsenti E, Nebreda AR, Vernos I. 2000. Xkid, a chromokinesin required for chromosome alignment on the metaphase plate. Cell 102: 425-435.

Aylett CHS, Wang Q, Michie KA, Amos LA, Löwe J. 2010. Filament structure of bacterial tubulin homologue TubZ. Proc Natl Acad Sci 107: 19766-19771.

Barry RM, Gitai Z. 2011. Self-assembling enzymes and the origins of the cytoskeleton. Curr Opin Microbiol 14: 704-711.

Bendezu FO, de Boer PAJ. 2008. Conditional lethality, division defects, membrane involution, and endocytosis in mre and mrd shape mutants of Escherichia coli. J Bacteriol 190: $1792-1811$

Berliner E, Young EC, Anderson K, Mahtani HK, Gelles J. 1995. Failure of a single-headed kinesin to track parallel to microtubule protofilaments. Nature 373: 718-721.

Bernander R, Lind AE, Ettema TJGE. 2011. An archaeal origin for the actin cytoskeleton: Implications for eukaryogenesis. Commun Integr Biol 4: 664-667.

Bieling P, Telley IA, Surrey T. 2010. A minimal midzone protein module controls formation and length of antiparallel microtubule overlaps. Cell 142: 420-432.

Bork P, Sander C, Valencia A. 1992. An ATPase domain common to prokaryotic cell cycle proteins, sugar kinases, actin, and hsp70 heat shock proteins. Proc Natl Acad Sci 89: 7290-7294.

Brokaw CJ. 2004. Computer simulation of flagellar movement IX. Oscillation and symmetry breaking in a model for short flagella and nodal cilia. Cell Motil Cytoskeleton 60: $35-47$ 
Carvalho-Santos Z, Machado P, Branco P, Tavares-Cadete F, Rodrigues-Martins A, Pereira-Leal JB, Bettencourt-Dias M. 2010. Stepwise evolution of the centriole-assembly pathway. J Cell Sci 123: 1414-1426.

Cavalier-Smith T. 2002. The phagotrophic origin of eukaryotes and phylogenetic classification of Protozoa. Int J Syst Evol Microbiol 52: 297-354.

Cavalier-Smith T. 2013. Early evolution of eukaryote feeding modes, cell structural diversity, and classification of the protozoan phyla Loukozoa, Sulcozoa, and Choanozoa. Eur J Protistol 49: 115-178.

Chalkia D, Nikolaidis N, Makalowski W, Klein J, Nei M. 2008. Origins and evolution of the formin multigene family that is involved in the formation of actin filaments. Mol Biol Evol 25: 2717-2733.

Chen Y, Bjornson K, Redick SD, Erickson HP. 2005. A rapid fluorescence assay for FtsZ assembly indicates cooperative assembly with a dimer nucleus. Biophys J 88: $505-$ 514.

Cooper JA, Schafer DA. 2000. Control of actin assembly and disassembly at filament ends. Curr Opin Cell Biol 12: $97-103$.

Dawson SC, Paredez AR. 2013. Alternative cytoskeletal landscapes: Cytoskeletal novelty and evolution in basal excavate protists. Curr Opin Cell Biol 25: 134-141.

Demonchy R, Blisnick T, Deprez C, Toutirais G, Loussert C, Marande W, Grellier P, Bastin P, Kohl L. 2009. Kinesin 9 family members perform separate functions in the trypanosome flagellum. J Cell Biol 187: 615-622.

Derman AI, Becker EC, Truong BD, Fujioka A, Tucey TM, Erb ML, Patterson PC, Pogliano J. 2009. Phylogenetic analysis identifies many uncharacterized actin-like proteins (Alps) in bacteria: Regulated polymerization, dynamic instability and treadmilling in Alp7A. Mol Microbiol 73: 534-552.

Domínguez-Escobar J, Chastanet A, Crevenna AH, Fromion V, Wedlich-Söldner R, Carballido-López R. 2011. Processive movement of MreB-associated cell wall biosynthetic complexes in bacteria. Science 333: 225-228.

Drew KRP, Pogliano J. 2011. Dynamic instability-driven centering/segregating mechanism in bacteria. Proc Nat Acad Sci 108: $11075-11080$.

Eckert C, Hammesfahr B, Kollmar M. 2011. A holistic phylogeny of the coronin gene family reveals an ancient or igin of the tandem-coronin, defines a new subfamily, and predicts protein function. BMC Evol Biol 11: 268.

Eme L, Moreira D, Talla E, Brochier-Armanet C. 2009. A complex cell division machinery was present in the last common ancestor of eukaryotes. PLoS ONE 4: e5021.

Ettema TJG, Lindås A-C, Bernander R. 2011. An actin-based cytoskeleton in archaea. Mol Microbiol 80: 1052-1061.

Fang X, Luo J, Nishihama R, Wloka C, Dravis C, Travaglia M, Iwase M, Vallen EA, Bi E. 2010. Biphasic targeting and cleavage furrow ingression directed by the tail of a myosin II. J Cell Biol 191: 1333-1350.

Fenton AK, Gerdes K. 2013. Direct interaction of FtsZ and MreB is required for septum synthesis and cell division in Escherichia coli. EMBO J 32: 1953-1965.

Frickey T, Lupas A. 2004. CLANS: A Java application for visualizing protein families based on pairwise similarity. Bioinformatics 20: 3702-3704.
Fritz-Laylin LK, Prochnik SE, Ginger ML, Dacks JB, Carpenter ML, Field MC, Kuo A, Paredez A, Chapman J, Pham J, et al. 2010. The genome of Naegleria gruberi illuminates early eukaryotic versatility. Cell 140: 631642.

Gandhi SR, Gierliński M, Mino A, Tanaka K, Kitamura E, Clayton L, Tanaka TU. 2011. Kinetochore-dependent microtubule rescue ensures their efficient and sustained interactions in early mitosis. Dev Cell 21: 920-933.

Garner EC. 2004. Dynamic instability in a DNA-segregating prokaryotic actin homolog. Science 306: 1021-1025.

Garner EC, Campbell CS, Weibel DB, Mullins RD. 2007. Reconstitution of DNA segregation driven by assembly of a prokaryotic actin homolog. Science 315: 1270-1274.

Garner EC, Bernard R, Wang W, Zhuang X, Rudner DZ, Mitchison T. 2011. Coupled, circumferential motions of the cell wall synthesis machinery and MreB filaments in B. subtilis. Science 333: 222-225.

Gayathri P, Fujii T, Møller-Jensen J, van den Ent F, Namba K, Löwe J. 2012. A bipolar spindle of antiparallel ParM filaments drives bacterial plasmid segregation. Science 338: $1334-1337$.

Goley ED, Welch MD. 2006. The ARP2/3 complex: An actin nucleator comes of age. Nat Rev Mol Cell Biol 7: 713-726.

Goodwin SS, Vale RD. 2010. Patronin regulates the microtubule network by protecting microtubule minus ends. Cell 143: 263-274.

Gordon D, Bernheim-Groswasser A, Keasar C, Farago O. 2012. Hierarchical self-organization of cytoskeletal active networks. Phys Biol 9: 026005.

Gruneberg U, Neef R, Li X, Chan EHY, Chalamalasetty RB, Nigg EA, Barr FA. 2006. KIF14 and citron kinase act together to promote efficient cytokinesis. J Cell Biol 172: $363-372$.

Halary S, McInerney JO, Lopez P, Bapteste E. 2013. EGN: A wizard for construction of gene and genome similarity networks. BMC Evol Biol 13: 146.

Hammesfahr B, Kollmar M. 2012. Evolution of the eukaryotic dynactin complex, the activator of cytoplasmic dynein. BMC Evol Biol 12: 95.

Holy TE, Leibler S. 1994. Dynamic instability of microtubules as an efficient way to search in space. Proc Natl Acad Sci 91: 5682-5685.

Holy TE, Dogterom M, Yurke B, Leibler S. 1997. Assembly and positioning of microtubule asters in microfabricated chambers. Proc Natl Acad Sci 94: 6228-6231.

Ingerson-Mahar M, Briegel A, Werner JN, Jensen GJ, Gitai Z. 2010. The metabolic enzyme CTP synthase forms cytoskeletal filaments. Nat Cell Biol 12: 739-746.

Iyer LM, Leipe DD, Koonin EV, Aravind L. 2004. Evolutionary history and higher order classification of $\mathrm{AAA}^{+}$ ATPases. J Struct Biol 146: 11-31.

Janson ME, Loughlin R, Loïodice I, Fu C, Brunner D, Nédélec FJ, Tran PT. 2007. Crosslinkers and motors organize dynamic microtubules to form stable bipolar arrays in fission yeast. Cell 128: 357-368.

Jékely G. 2003. Small GTPases and the evolution of the eukaryotic cell. Bioessays 25: 1129-1138.

Jékely G. 2007. Origin of phagotrophic eukaryotes as social cheaters in microbial biofilms. Biol Direct 2: 3. 
Jékely G. 2008. Origin of the nucleus and Ran-dependent transport to safeguard ribosome biogenesis in a chimeric cell. Biol Direct 3: 31.

Jékely G. 2013. Global view of the evolution and diversity of metazoan neuropeptide signaling. Proc Natl Acad Sci 110: 8702-8707.

Jékely G, Arendt D. 2006. Evolution of intraflagellar transport from coated vesicles and autogenous origin of the eukaryotic cilium. Bioessays 28: 191-198.

Jenkins C, Samudrala R, Anderson I, Hedlund BP, Petroni G, Michailova N, Pinel N, Overbeek R, Rosati G, Staley JT. 2002. Genes for the cytoskeletal protein tubulin in the bacterial genus Prosthecobacter. Proc Natl Acad Sci 99: 17049-17054.

Jiang K, Akhmanova A. 2011. Microtubule tip-interacting proteins: A view from both ends. Curr Opin Cell Biol 23: 94-101.

Kalliomaa-Sanford AK, Rodriguez-Castañeda FA, McLeod BN, Latorre-Roselló V, Smith JH, Reimann J, Albers SV, Barillà D. 2012. Chromosome segregation in Archaea mediated by a hybrid DNA partition machine. Proc Natl Acad Sci 109: 3754-3759.

Kapitein LC, Peterman EJG, Kwok BH, Kim JH, Kapoor TM, Schmidt CF. 2005. The bipolar mitotic kinesin Eg5 moves on both microtubules that it crosslinks. Nature 435: $114-118$.

Karsenti E, Nédélec F, Surrey T. 2006. Modelling microtubule patterns. Nat Cell Biol 8: 1204-1211.

Kim SY, Gitai Z, Kinkhabwala A, Shapiro L, Moerner WE. 2006. Single molecules of the bacterial actin MreB undergo directed treadmilling motion in Caulobacter crescentus. Proc Natl Acad Sci 103: 10929-10934.

Kollman JM, Merdes A, Mourey L, Agard DA. 2011. Microtubule nucleation by $\gamma$-tubulin complexes. Nat Rev Mol Cell Biol 12: 709-721.

Komeili A, Li Z, Newman DK, Jensen GJ. 2006. Magnetosomes are cell membrane invaginations organized by the actin-like protein MamK. Science 311: 242-245.

Kueh HY, Mitchison TJ. 2009. Structural plasticity in actin and tubulin polymer dynamics. Science 325: 960-963.

Kull FJ, Sablin EP, Lau R, Fletterick RJ, Vale RD. 1996. Crystal structure of the kinesin motor domain reveals a structural similarity to myosin. Nature 380: 550-555.

Kurasawa Y, Earnshaw WC, Mochizuki Y, Dohmae N, Todokoro K. 2004. Essential roles of KIF4 and its binding partner PRC1 in organized central spindle midzone formation. EMBO J 23: 3237-3248.

Lane N, Martin W. 2010. The energetics of genome complexity. Nature 467: 929.

Larsen RA, Cusumano C, Fujioka A, Lim-Fong G, Patterson P, Pogliano J. 2007. Treadmilling of a prokaryotic tubulinlike protein, TubZ, required for plasmid stability in $B a-$ cillus thuringiensis. Genes Dev 21: 1340-1352.

Lechtreck K-F, Johnson EC, Sakai T, Cochran D, Ballif BA, Rush J, Pazour GJ, Ikebe M, Witman GB. 2009. The Chlamydomonas reinhardtii BBSome is an IFT cargo required for export of specific signaling proteins from flagella. $J$ Cell Biol 187: 1117-1132.

Leibler S, Nédélec FJ, Surrey T, Maggs AC. 1997. Self-organization of microtubules and motors. Nature 389: $305-$ 308.
Leipe DD, Wolf YI, Koonin EV, Aravind L. 2002. Classification and evolution of P-loop GTPases and related ATPases. J Mol Biol 317: 41-72.

Leonardy S, Miertzschke M, Bulyha I, Sperling E, Wittinghofer A, Søgaard-Andersen L. 2010. Regulation of dynamic polarity switching in bacteria by a Ras-like Gprotein and its cognate GAP. EMBO J 29: 2276-2289.

Lim GE, Derman AI, Pogliano J. 2005. Bacterial DNA segregation by dynamic SopA polymers. Proc Natl Acad Sci 102: $17658-17663$.

Löwe J, Amos LA. 1998. Crystal structure of the bacterial cell-division protein FtsZ. Nature 391: 203-206.

Löwe J, Amos LA. 1999. Tubulin-like protofilaments in $\mathrm{Ca}^{2+}$-induced FtsZ sheets. EMBO J 18: 2364-2371.

Löwe J, Amos LA. 2009. Evolution of cytomotive filaments: The cytoskeleton from prokaryotes to eukaryotes. Int $J$ Biochem Cell Biol 41: 323-329.

Lutkenhaus J, Pichoff S, Du S. 2012. Bacterial cytokinesis: From Z ring to divisome. Cytoskeleton 69: 778-790.

Makarova KS, Yutin N, Bell SD, Koonin EV. 2010. Evolution of diverse cell division and vesicle formation systems in Archaea. Nat Rev Microbiol 8: 731-741.

McIntosh JR, Volkov V, Ataullakhanov FI, Grishchuk EL. 2010. Tubulin depolymerization may be an ancient biological motor. J Cell Sci 123: 3425-3434.

Mercier R, Kawai Y, Errington J. 2013. Excess membrane synthesis drives a primitive mode of cell proliferation. Cell 152: 997-1007.

Mirabeau O, Joly JS. 2013. Molecular evolution of peptidergic signaling systems in bilaterians. Proc Natl Acad Sci 110: E2028-E2037.

Mitchell DR. 2004. Speculations on the evolution of $9+2$ organelles and the role of central pair microtubules. Biol Cell 96: 691-696.

Mitchell DR, Kang Y. 1991. Identification of oda6 as a Chlamydomonas dynein mutant by rescue with the wild-type gene. J Cell Biol 113: 835-842.

Mitchison T, Kirschner M. 1984. Dynamic instability of microtubule growth. Nature 312: 237-242.

Mullins RD, Heuser JA, Pollard TD. 1998. The interaction of Arp2/3 complex with actin: Nucleation, high affinity pointed end capping, and formation of branching networks of filaments. Proc Natl Acad Sci 95: 6181-6186.

Nédélec F. 2002. Computer simulations reveal motor properties generating stable antiparallel microtubule interactions. J Cell Biol 158: 1005-1015.

Nédélec F, Surrey T, Karsenti E. 2003. Self-organisation and forces in the microtubule cytoskeleton. Curr Opin Cell Biol 15: 118-124.

Neuwald AF, Landsman D. 1997. GCN5-related histone Nacetyltransferases belong to a diverse superfamily that includes the yeast SPT10 protein. Trends Biochem Sci 22: 154-155.

Niwa S, Nakajima K, Miki H, Minato Y, Wang D, Hirokawa N. 2012. KIF19A is a microtubule-depolymerizing kinesin for ciliary length control. Dev Cell 23: 1167-1175.

Noree C, Sato BK, Broyer RM, Wilhelm JE. 2010. Identification of novel filament-forming proteins in Saccharomyces cerevisiae and Drosophila melanogaster. J Cell Biol 190: 541-551. 
Okada Y, Hirokawa N. 1999. A processive single-headed motor: Kinesin superfamily protein KIF1A. Science 283: 1152-1157.

Osawa M, Anderson DE, Erickson HP. 2009. Curved FtsZ protofilaments generate bending forces on liposome membranes. EMBO J 28: 3476-3484.

Pal C, Papp B, Lercher MJ. 2005. Adaptive evolution of bacterial metabolic networks by horizontal gene transfer. Nat Genet 37: 1372-1375.

Petry S, Groen AC, Ishihara K, Mitchison TJ, Vale RD. 2013. Branching microtubule nucleation in Xenopus egg extracts mediated by augmin and TPX2. Cell 152: 768-777.

Pilhofer M, Jensen GJ. 2013. The bacterial cytoskeleton: More than twisted filaments. Curr Opin Cell Biol 25: $125-133$.

Pilhofer M, Ladinsky MS, McDowall AW, Petroni G, Jensen GJ. 2011. Microtubules in bacteria: Ancient tubulins build a five-protofilament homolog of the eukaryotic cytoskeleton. PLOS Biol 9: e1001213.

Popp D, Iwasa M, Erickson HP, Narita A, Maéda Y, Robinson RC. 2010a. Suprastructures and dynamic properties of Mycobacterium tuberculosis FtsZ. J Biol Chem 285: 11281-11289.

Popp D, Narita A, Ghoshdastider U, Maeda K, Maéda Y, Oda T, Fujisawa T, Onishi H, Ito K, Robinson RC. 2010b. Polymeric structures and dynamic properties of the bacterial actin AlfA. J Mol Biol 397: 1031-1041.

Popp D, Narita A, Maeda K, Fujisawa T, Ghoshdastider U, Iwasa M, Maeda Y, Robinson RC. 2010c. Filament structure, organization, and dynamics in MreB sheets. J Biol Chem 285: 15858-15865.

Popp D, Narita A, Lee LJ, Larsson M, Robinson RC. 2012. Microtubule-like properties of the bacterial actin homolog ParM-R1. J Biol Chem 287: 37078-37088.

Ptacin JL, Lee SF, Garner EC, Toro E, Eckart M, Comolli LR, Moerner WE, Shapiro L. 2010. A spindle-like apparatus guides bacterial chromosome segregation. Nat Cell Biol 12: 791-798.

Raikov IB. 1994. The diversity of forms of mitosis in protozoa: A comparative review. Eur J Protistol 30: 253-269.

Ramesh MA, Malik S-B, Logsdon JM Jr. 2005. A phylogenomic inventory of meiotic genes. Curr Biol 15: 185-191.

Richards T, Cavalier-Smith T. 2005. Myosin domain evolution and the primary divergence of eukaryotes. Nature 436: $1113-1118$.

Rivero F, Cvrcková F. 2007. Origins and evolution of the actin cytoskeleton. Adv Exp Med Biol 607: 97-110.

Salje J, Löwe J. 2008. Bacterial actin: Architecture of the ParMRC plasmid DNA partitioning complex. EMBO J 27: 2230-2238.

Satir P, Mitchell DR, Jékely G. 2008. How did the cilium evolve? Curr Top Dev Biol 85: 63-82.

Schlieper D, Oliva M, Andreu J, Löwe J. 2005. Structure of bacterial tubulin BtubA/B: Evidence for horizontal gene transfer. Proc Natl Acad Sci 102: 9170-9175.

Schutt CE, Myslik JC, Rozycki MD, Goonesekere NC, Lindberg U. 1993. The structure of crystalline profilin- $\beta$-actin. Nature 365: 810-816.

Sharp DJ, Ross JL. 2012. Microtubule-severing enzymes at the cutting edge. J Cell Sci 125: 2561-2569.
Shaw SL. 2003. Sustained microtubule treadmilling in arabidopsis cortical arrays. Science 300: 1715-1718.

Soldati T, Schliwa M. 2006. Powering membrane traffic in endocytosis and recycling. Nat Rev Mol Cell Biol 7: 897-908.

Steczkiewicz K, Kinch L, Grishin NV, Rychlewski L, Ginalski K. 2006. Eukaryotic domain of unknown function DUF738 belongs to Gcn5-related $N$-acetyltransferase superfamily. Cell Cycle 5: 2927-2930.

Strauss MP, Liew ATF, Turnbull L, Whitchurch CB, Monahan LG, Harry EJ. 2012. 3D-SIM super resolution microscopy reveals a bead-like arrangement for FtsZ and the division machinery: Implications for triggering cytokinesis. PLOS Biol 10: e1001389.

Surrey T. 2001. Physical properties determining self-organization of motors and Microtubules. Science 292: $1167-$ 1171.

Suryavanshi S, Eddé B, Fox LA, Guerrero S, Hard R, Hennessey T, Kabi A, Malison D, Pennock D, Sale WS, et al. 2010. Tubulin glutamylation regulates ciliary motility by altering inner dynein arm activity. Curr Biol 20: 435-440.

Szwedziak P, Wang Q, Freund SM, Löwe J. 2012. FtsA forms actin-like protofilaments. EMBO J 31: 2249-2260.

Takada S, Kamiya R. 1994. Functional reconstitution of Chlamydomonas outer dynein arms from $\alpha-\beta$ and $\gamma$-subunits: Requirement of a third factor. J Cell Biol 126: 737-745.

Takenawa T, Miki H. 2001. WASP and WAVE family proteins: Key molecules for rapid rearrangement of cortical actin filaments and cell movement. J Cell Sci 114: 1801-1809.

Tanaka TU, Rachidi N, Janke C, Pereira G, Galova M, Schiebel E, Stark MJR, Nasmyth K. 2002. Evidence that the Ipl1-Sli15 (Aurora kinase-INCENP) complex promotes chromosome bi-orientation by altering kinetochorespindle pole connections. Cell 108: 317-329.

Tanenbaum ME, Macůrek L, Janssen A, Geers EF, AlvarezFernández M, Medema RH. 2009. Kif15 cooperates with eg5 to promote bipolar spindle assembly. Curr Biol 19: 1703-1711.

Taschner M, Vetter M, Lorentzen E. 2012. Atomic resolution structure of human $\alpha$-tubulin acetyltransferase bound to acetyl-CoA. Proc Natl Acad Sci 109: 19649-19654.

Thanbichler M, Shapiro L. 2008. Getting organized-How bacterial cells move proteins and DNA. Nat Rev Microbiol 6: $28-40$.

Tollis S, Dart AE, Tzircotis G, Endres RG. 2010. The zipper mechanism in phagocytosis: Energetic requirements and variability in phagocytic cup shape. BMC Syst Biol 4: 149.

Tran PT, Marsh L, Doye V, Inoué S, Chang F. 2001. A mechanism for nuclear positioning in fission yeast based on microtubule pushing. J Cell Biol 153: 397-411.

Vale RD. 2003. The molecular motor toolbox for intracellular transport. Cell 112: 467-480.

Vale RD, Milligan RA. 2000. The way things move: Looking under the hood of molecular motor proteins. Science 288: 88-95.

Van den Ent F, Amos LA, Löwe J. 2001. Prokaryotic origin of the actin cytoskeleton. Nature 413: 39-44.

Vater CA, Raymond CK, Ekena K, Howald-Stevenson I, Stevens TH. 1992. The VPS1 protein, a homolog of dynamin required for vacuolar protein sorting in Saccharomyces 
G. Jékely

cerevisiae, is a GTPase with two functionally separable domains. J Cell Biol 119: 773-786.

Vignaud T, Blanchoin L, Théry M. 2012. Directed cytoskeleton self-organization. Trends Cell Biol 22: 671-682.

Wang S, Arellano-Santoyo H, Combs PA, Shaevitz JW. 2010 Actin-like cytoskeleton filaments contribute to cell mechanics in bacteria. Proc Natl Acad Sci 107: 9182-9185.

Wegner A. 1976. Head to tail polymerization of actin. J Mol Biol 108: 139-150.

Wehrl W, Niederweis M, Schumann W. 2000. The FtsH protein accumulates at the septum of Bacillus subtilis during cell division and sporulation. J Bacteriol 182: 3870-3873.

Wickstead B, Gull K. 2007. Dyneins across eukaryotes: A comparative genomic analysis. Traffic 8: 1708-1721.
Wickstead B, Gull K. 2011. Evolution: The evolution of the cytoskeleton. J Cell Biol 194: 513-525.

Wickstead B, Gull K, Richards TA. 2010. Patterns of kinesin evolution reveal a complex ancestral eukaryote with a multifunctional cytoskeleton. BMC Evol Biol 10: 110.

Wolf YI, Koonin EV. 2012. A tight link between orthologs and bidirectional best hits in bacterial and archaeal genomes. Genome Biol Evol 4: 1286-1294.

Yutin N, Koonin EV. 2012. Archaeal origin of tubulin. Biol Direct 7: 10.

Yutin N, Wolf MY, Yuri I Wolf, Koonin EV. 2009. The origins of phagocytosis and eukaryogenesis. Biol Direct 4: 9. 


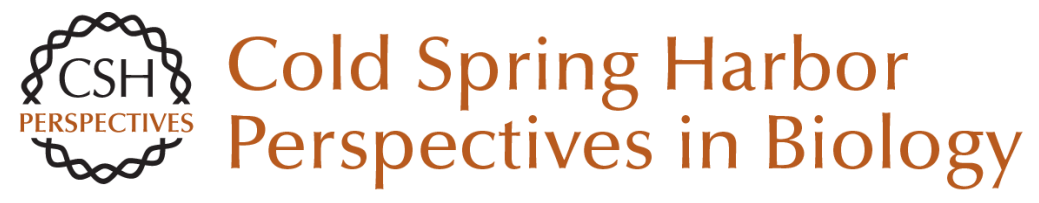

\section{Origin and Evolution of the Self-Organizing Cytoskeleton in the Network of Eukaryotic Organelles}

Gáspár Jékely

Cold Spring Harb Perspect Biol 2014; doi: 10.1101/cshperspect.a016030

Subject Collection The Origin and Evolution of Eukaryotes

The Persistent Contributions of RNA to

Eukaryotic Gen(om)e Architecture and Cellular

Function

Jürgen Brosius

Green Algae and the Origins of Multicellularity in the Plant Kingdom James G. Umen

The Archaeal Legacy of Eukaryotes: A Phylogenomic Perspective Lionel Guy, Jimmy H. Saw and Thijs J.G. Ettema

Origin and Evolution of the Self-Organizing Cytoskeleton in the Network of Eukaryotic Organelles Gáspár Jékely

On the Age of Eukaryotes: Evaluating Evidence from Fossils and Molecular Clocks

Laura Eme, Susan C. Sharpe, Matthew W. Brown, et al.

Origin of Spliceosomal Introns and Alternative Splicing

Manuel Irimia and Scott William Roy
Eukaryotic Origins: How and When Was the

Mitochondrion Acquired?

Anthony M. Poole and Simonetta Gribaldo

Bacterial Influences on Animal Origins

Rosanna A. Alegado and Nicole King

Missing Pieces of an Ancient Puzzle: Evolution of the Eukaryotic Membrane-Trafficking System Alexander Schlacht, Emily K. Herman, Mary J. Klute, et al.

The Neomuran Revolution and Phagotrophic Origin of Eukaryotes and Cilia in the Light of Intracellular Coevolution and a Revised Tree of Life

Thomas Cavalier-Smith

Protein Targeting and Transport as a Necessary Consequence of Increased Cellular Complexity Maik S. Sommer and Enrico Schleiff

How Natural a Kind Is "Eukaryote?" W. Ford Doolittle

For additional articles in this collection, see http://cshperspectives.cshlp.org/cgi/collection/

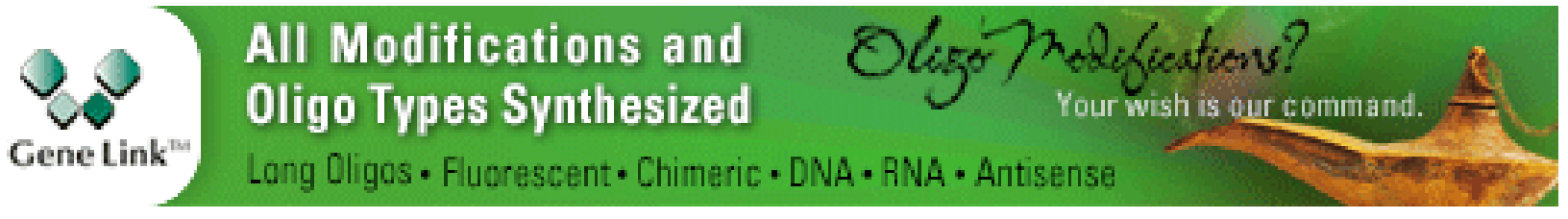


Protein and DNA Modifications: Evolutionary Imprints of Bacterial Biochemical Diversification and Geochemistry on the Provenance of Eukaryotic Epigenetics

L. Aravind, A. Maxwell Burroughs, Dapeng Zhang, et al.

The Eukaryotic Tree of Life from a Global Phylogenomic Perspective Fabien Burki
What Was the Real Contribution of

Endosymbionts to the Eukaryotic Nucleus?

Insights from Photosynthetic Eukaryotes David Moreira and Philippe Deschamps

Bioenergetic Constraints on the Evolution of Complex Life

Nick Lane

For additional articles in this collection, see http://cshperspectives.cshlp.org/cgi/collection/

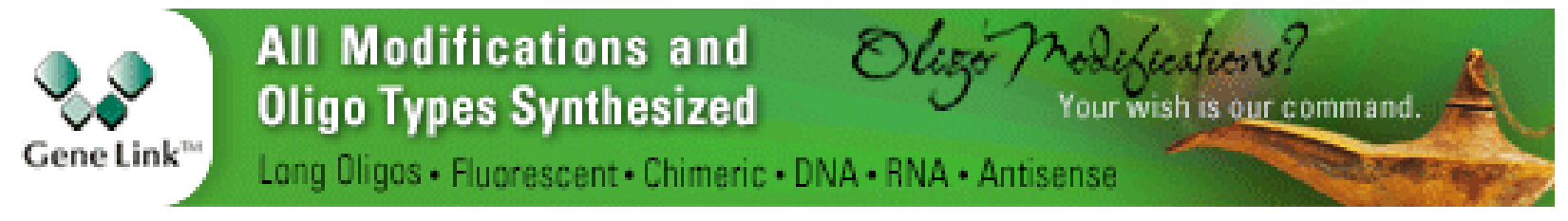

Copyright @ 2014 Cold Spring Harbor Laboratory Press; all rights reserved 